\title{
Structural Basis for Explaining Open-Channel Blockade of the NMDA Receptor
}

\author{
Masoud M. Zarei and John A. Dani \\ Division of Neuroscience, Baylor College of Medicine, Houston, Texas 77030-3
}

\begin{abstract}
The open-channel structure of the $N$-methyl-D-aspartate (NMDA) receptor was investigated to explain apparently conflicting interpretations about ionic interactions within the pore. Patch-clamp techniques were applied to tissuecultured rat hippocampal neurons from the CA1 region. A wide range of ammonium derivatives was studied to learn about the structure of the pore from permeability and openchannel blocking characteristics. We conclude that the pore is asymmetric, having higher-affinity binding for organic cations from the outside and having a larger external entrance. The minimum cross-sectional area of the pore is rectangular $(\approx 0.45 \times 0.57 \mathrm{~nm})$ and is the single-occupancy binding site(s) for small permeant cations. The narrow region extending from this minimum cross section is short, and its shape underlies the voltage dependencies of blocking cations. While occupying the blocking site, some openchannel blockers can interact with permeant cations at their binding site in the minimum cross section. A structurally based hypothesis is presented, explaining that the electrostatic interactions between the blocking site and permeant-ion site produce a high voltage dependence for blockade by some cations.
\end{abstract}

[Key words: glutamate receptors, NMDA receptors, ion channel, structure and function, ion permeation, ion selectivity, $\mathbf{M g}^{2+}$ blockade, hippocampal neurons]

$N$-methyl-D-aspartate (NMDA) receptors comprise a subtype of glutamate receptors that are ligand-gated cation-selective channels, highly permeable to $\mathrm{Ca}^{2+}$, and blocked by $\mathrm{Mg}^{2+}$ in a voltage-dependent manner (Mayer et al., 1984; Nowak et al., 1984; MacDermott et al., 1986; Jahr and Stevens, 1990; Johnson and Ascher, 1990). These ion permeability properties underlie the initiation of long-term potentiation by NMDA receptors at some excitatory pathways (reviews: Madison et al., 1991; Bliss and Collingridge, 1993). Although the $\mathrm{Ca}^{2+}$ permeability and blockade by $\mathrm{Mg}^{2+}$ have been well characterized and site-directed mutagenesis has shown the importance of particular amino acids (Burnashev et al., 1992; Mori et al., 1992), the structural basis and molecular mechanisms for these and related properties are controversial.

Ion permeation and blockade of the channel depend most strongly on ion binding within the narrow region of the pore.

\footnotetext{
Received June 10, 1994; accepted Aug. 15, 1994.

This work was supported by the Muscular Dystrophy Association and by the NIH through a grant from NINDS, NS21229.

Correspondence should be addressed to John A. Dani, Division of Neuroscience, Baylor College of Medicine, One Baylor Plaza, Houston, TX 77030-3.

Copyright (C) 1995 Society for Neuroscience $0270-6474 / 95 / 151446-09 \$ 05.00 / 0$
}

There are conflicting interpretations about ion binding sites that are directly in the permeation pathway. The interpretation of some work is that there are multiple sites in the narrow region and that important permeant cations (such as $\mathrm{Ca}^{2+}$ ) and blockers (such as $\mathbf{M g}^{2+}$, ketamine, and MK-801) bind and interact (Ascher and Nowak, 1988; Mayer et al., 1988; Reynolds and Miller, 1988). Interaction between sites produces the high voltage dependence seen for open-channel blockade of the NMDA receptor. For example, when $\mathrm{Mg}^{2+}$ was applicd first to the outside of the channel, then the inside, the proportion of the field sensed from the two sides added up to greater than $100 \%$, suggesting that the blocking ion is coupled to the movement of permeant ions (Ascher and Nowak, 1988; Johnson and Ascher, 1990). Other evidence, though not collected to address this issue, may be interpreted in terms of a competition among ions for single occupancy of binding sites (Wong et al., 1986; Mayer and Westbrook, 1987; Sernagor et al., 1989). In addition, permeability ratio, anomalous mole fraction, and conductance measurements showed that for small permeant cations the NMDA receptor behaves as though there is single occupancy of the site(s) within the narrow region of the pore (Zarei and Dani, 1994).

The purpose of this study is to examine blockade in terms of the open-channel structure to provide a basis for a unifying explanation of the apparently disparate conclusions. NMDA receptors from CAl rat hippocampal neurons were studied. Because the narrowest cross section of the pore is the main determinant for ion permeation and blockade, we determined the area and general shape of the minimum cross section. Tetramethylammonium (TMA) was determined to be the simplest impermeant cation that cannot pass through the narrow region. TMA and progressively larger tetra-n-alkylammonium derivatives were then used to analyze the blockade in terms of the size of the pore leading up to the narrowest region from both sides of the membrane.

We conclude that the narrowest region has a short length and rectangular shape with an area of $0.26 \mathrm{~nm}^{2}$. This region binds one small permeant cation at a time. Some blocking ions of a particular size that are too large to pass through the narrowest region can settle into a binding site just external to the binding site for permeant cations. The electrostatic interaction between those sites causes the unusually high voltage dependence for blockade by some cations, including $\mathrm{Mg}^{2+}$, tetraethylammonium, and others.

\section{Materials and Methods}

Tissue culture. Hippocampal neurons were cultured using standard techniques (adapted from Huettner and Baughman, 1986; Amador and Dani, 1991a). The CA1 region was dissected from the hippocampus of two Sprague-Dawley rats (postnatal day $1-2$ ), and the isolated CA1 tissue 
was transferred into an enzyme solution containing $10 \mathrm{ml}$ of Earl's balanced salt solution and 200 units of papain for approximately 30 min. The tissue was washed several times with complete media containing $2.5 \mathrm{mg} / \mathrm{ml}$ trypsin inhibitor and bovine serum albumin, and then gently triturated. Complete media was composed of MEM, $292 \mu \mathrm{g} / \mathrm{ml}$ glutamine, $5 \%$ heat-inactivated fetal bovine serum, 50 units $/ \mathrm{ml}$ penicillin, $50 \mu \mathrm{g} / \mathrm{ml}$ streptomycin, $20 \mathrm{~mm}$ glucose, and $1 \mu \mathrm{l} / \mathrm{ml}$ serum extender. The cells were plated onto coverslips that had been coated with collagen and poly-d-lysine and exposed to ultraviolet light for $30 \mathrm{~min}$. After 3 $\mathrm{d}$, the cells were treated for $2 \mathrm{~d}$ with $5 \mu \mathrm{M}$ cytosine arabinofuranoside. The cells were maintained in complete media in an incubator at $37^{\circ} \mathrm{C}$, $5 \% \mathrm{CO}_{2}$, and the media was changed every $3 \mathrm{~d}$. The cells were used between 6 to $9 \mathrm{~d}$ after plating. Although the cells were healthy for a much longer period of time, they were used early and for only a few days so that the cells had short processes, allowing better voltage-clamp control.

Solutions. The external test solutions for determining the area of the minimum cross section contained $150 \mathrm{mM}$ of the organic test cation plus $10 \mathrm{~mm}$ HEPES, $50 \mu \mathrm{M}$ picrotoxin, $1 \mu \mathrm{M}$ strychnine, $0.5 \mu \mathrm{M}$ tetrodotoxin, and $2 \mu \mathrm{M}$ 6-cyano-7-nitroquinoxaline-2,3-dione (CNQX, Tocris Neuramin, England; Honore et al., 1988). The $\mathrm{pH}$ was adjusted to 7.0 usually with the hydroxide of the test cation, and the anion was chloride. Whole-cell inward currents were induced by $20-80 \mu \mathrm{M}$ NMDA with 10-20 $\mu \mathrm{M}$ glycinc, while the potential was held between -40 to $-100 \mathrm{mV}$. The bath was $150 \mathrm{mM} \mathrm{CsCl}, 0.5 \mathrm{mM} \mathrm{CaCl}_{2}, 10 \mathrm{mM}$ HEPES, plus inhibitors.

The size of the narrowest cross section was determined by measuring inward current carried by poorly permeant organic cations in the external solution. Therefore, we put impermeant solutions inside the cell so that the reversal potential would be positive even with poorly permeant external cations. In that way, large inward driving forces were ensured without having to hold the potential at extremely negative values. For the tests and controls, three different internal solutions were used to be certain no unexpected artifacts were arising from the impermeant internal solutions. Two of the solutions were similar (mM): $145 \mathrm{~N}$-methylD-glucamine (NMDG), 5 TEA chloride, 5 EDTA, 5 EGTA, and 10 HEPES; or NMDG and TEA were replaced by TMA. The main anion was methanesulfonate that was used to achieve a $\mathrm{pH}$ of 7 . The third internal solution contained (mM) 150 choline chloride, 5 EDTA, 5 EGTA, and 10 HEPES, and the pH was brought to 7.0 by choline hydroxide. The osmolality of all solutions was adjusted to 0.36 osmolal with sucrose.

The voltage-dependent blockade of the NMDA receptor channel was studied using four different tetra- $n$-alkylammonium derivatives. For whole-cell and outside-out patch experiments, the external solutions contained (mM) 150 tetra- $n$-alkylammonium, $50 \mathrm{CsCl}, 1 \mathrm{EDTA}, 10 \mathrm{HE}$ PES, $50 \mu \mathrm{M}$ picrotoxin, $1 \mu \mathrm{M}$ strychnine, and $0.5 \mu \mathrm{M}$ tetrodotoxin. The control solution had the same composition as the above solution but contained none of the tetra-n-alkylammonium. Appropriate ratios of the control and the blocker solutions were mixed to obtain different blocker concentrations. The internal solution contained (mM) $50 \mathrm{CsCl}, 1$ EDTA, 4 EGIA, and 10 HEPES. To study internal blockade with inside-out patches, the external solutions bathing the inner surface of the membrane contained (mM) 150 tetra- $n$-alkylammonium, $50 \mathrm{CsCl}, 1 \mathrm{EDTA}$, 4 EGTA, and 10 HEPES, and the control solution had the same composition but without tetra- $n$-alkylammonium cations. The pipette solution bathing the outer surface of the membrane contained (mM) $50 \mathrm{CsCl}$, 10 HEPES, $50 \mu \mathrm{M}$ picrotoxin, $1 \mu \mathrm{M}$ strychnine, $0.5 \mu \mathrm{M}$ tetrodotoxin, 1 $\mu \mathrm{M}$ glycine, and $2 \mu \mathrm{M}$ NMDA. The bath was $150 \mathrm{~mm} \mathrm{CsCl}, 0.5 \mathrm{~mm}$ $\mathrm{CaCl}_{2}$, and $10 \mathrm{~mm}$ HEPES plus inhibitors. The $\mathrm{pH}$ of these solutions was adjusted to 7.4 with $\mathrm{CsOH}$, and the osmolality was adjusted to 0.4 osmolal with sucrose.

Recording techniques. Whole-cell and single-channel NMDA receptor currents were measured using standard patch-clamp techniques (Hamill et al., 1981; Dani, 1989). Electrodes were pulled with a twostage electrode puller (PP-83; Narishige USA, Inc., Greenvale, NY) using Garner Glass 7052, and were coated with Sylgard silicon elastomer (Dow Corning Corp., Midland, MI). The tips of the electrodes were polished immediately before use. The resistances of the electrodes were between 2 and $5 \mathrm{M} \Omega$ in standard solutions.

Currents were amplified and filtered using an Axopatch 1B or 1D voltage clamp with a four-pole Bessel filter (Axon Inst., Foster City, CA). Currents were digitally sampled with a 12-bit analog-to-digital converter (TL-1; Axon Inst.). The computer system delivered the holding potentials through a 12-bit digital-to-analog output. Whole-cell cur- rents were sampled every $1.5-6 \mathrm{msec}$, and single-channel currents were sampled every $0.1 \mathrm{msec}$. Various filter settings were used.

For whole-cell experiments, measurements in test solutions were always bracketed by measurements in a control solution. The main charge-carrying ion in control solutions was $\mathrm{Cs}^{+}$. Because the solution in the patch pipette was often very different from the cytoplasmic electrolyte, more than $8 \mathrm{~min}$ was allowed for the pipette electrolyte to diffuse throughout the cell. By following the shift in the reversal potential, it was found that a steady value was reached after $6 \mathrm{~min}$ in large cells, indicating that the internal exchange of electrolyte was sufficiently complete in less than $6 \mathrm{~min}$ with the smaller cells that were used in the experiments described here. All the experiments were conducted at room temperature, $23^{\circ} \mathrm{C}$. In all experiments, the liquid junction potentials were measured, and the holding potentials were corrected before plotting the data. Depending on the solutions, the liquid junction potentials varied from 0 to $7 \mathrm{mV}$.

Analysis of voltage-dependent blockade. In whole-cell and outsideout patches, $50 \mathrm{mM} \mathrm{Cs}^{+}$bathed the inside and outside of the cell, and different concentrations of a tetra- $n$-alkylammonium cation were added to the external test solutions. In inside-out patches similar solutions were used, and the tetra- $n$-alkylammonium compounds were added individually into the external solutions that bathed the cytoplasmic side of the NMDA receptor channel. The control solution contained no tetra$n$-alkylammonium blocker. In each experiment, the block was calculated by constructing the current-voltage relation. The results were fitted by the single-site equation (Woodhull, 1973; Johnson and Asher, 1990; Amador and Dani, 1991b):

$$
I_{b}=\frac{I_{c}}{1+\frac{[B]}{K_{d} \exp (\delta z F V / R T)},}
$$

where $I_{b}$ is the current with blocker present, and $I_{c}$ represents the control current in the absence of blocker. $K_{d}$ is the apparent dissociation constant of the blockers at $0 \mathrm{mV}$, and $[B]$ stands for blocker concentration. $R, T, z$, and $F$ have their conventional values, and $\delta$ is the fraction of the membrane field sensed by the blocking ions. Equation 1 can be rewritten to separate the voltage term from the concentration and binding terms:

$$
\frac{K_{d}}{[B]}\left(\frac{I_{c}}{I_{b}}-1\right)=\exp (-\delta z F V / R T)
$$

For simplicity, the left term will be called "block," and for Figures 4 and 5 the "block" term is normalized to the block that would be seen when $100 \%$ of the membrane field is sensed at the highest positive or negative holding potential that was studied. In experiments where the blockers are applied intracellularly, the term $\delta z F V / R T$ is multiplied by a negative sign. Equation 2 simplifies the presentation of the data by allowing the voltage-dependence term $(\delta)$ to be judged separate from the binding affinity of the blocking cation. In that way, data obtained with different concentrations of blockers can be combined and presented together.

The blockade by TMA, TEA, and TPA is rapid relative to ion permeation, so the amplitude of the single-channel currents was smaller. The analysis in that case is straightforward using Equation 2. TBA, however, had a higher affinity that produced flickery block because the rate of TBA leaving the blocking site is slow enough to be resolved by single-channel current measurements. These single-channel currents were analyzed by determining the burst length, integrating the current for that time, and determining the average current during that time interval. That method is equivalent to the analysis for the faster blockers TMA, TEA, and TPA.

Finally, the size of the ammonium compounds was estimated by building CPK space-filling models. The minimum cross-sectional area of each compound was estimated by measuring the CPK model and by finding the smallest two-dimensional slot that the CPK model could fit through. This method was the most direct way of estimating the twodimensional area of the minimum cross section of the NMDA receptor pore.

\section{Results}

Narrowest cross-sectional area of the NMDA pore

The first step to resolve the conflicting interpretations about ion binding and blockade requires a structural determination of the 


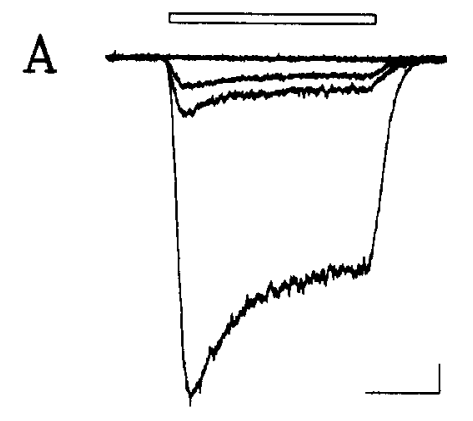

$$
\begin{aligned}
& \left(\mathrm{HOCH}_{2} \mathrm{CH}_{2}\right)_{3} \mathrm{~N}^{+} \mathrm{H} \\
& \left(\mathrm{HOCH}_{2} \mathrm{CH}_{2}\right)_{2} \mathrm{~N}^{+} \mathrm{HCH}_{3} \\
& \mathrm{HOCH}_{2} \mathrm{CH}_{2} \mathrm{~N}^{+} \mathrm{H}\left(\mathrm{CH}_{3}\right)_{2} \\
& \left(\mathrm{HOCH}_{2} \mathrm{CH}_{2}\right)_{2} \mathrm{~N}^{+} \mathrm{H}_{2}
\end{aligned}
$$

\begin{tabular}{|c|c|c|}
\hline External cations & $\begin{array}{l}\text { Trials/ } \\
\text { patches }\end{array}$ & Size $(\AA)$ \\
\hline \multicolumn{3}{|l|}{ Permeant cations } \\
\hline$\left(\mathrm{HOCH}_{2} \mathrm{CH}_{2}\right)_{2} \mathrm{~N}^{+} \mathrm{H}_{2}$ & $11 / 6$ & $4.1 \times 4.1$ \\
\hline$\left(\mathrm{CH}_{3}\right)_{3} \mathrm{~N}^{+} \mathrm{H}$ & $5 / 3$ & $4.5 \times 5.4$ \\
\hline $\mathrm{HOCH}_{2} \mathrm{CH}_{2} \mathrm{~N}+\mathrm{H}\left(\mathrm{CH}_{3}\right)_{2}$ & $24 / 11$ & $4.5 \times 5.4$ \\
\hline $\mathrm{CH}_{3} \mathrm{CH}_{2} \mathrm{~N}^{+} \mathrm{H}\left(\mathrm{CH}_{3}\right)_{2}$ & $13 / 4$ & $4.5 \times 5.4$ \\
\hline$\left(\mathrm{HOCH}_{2} \mathrm{CH}_{2}\right)_{2} \mathrm{~N}^{+} \mathrm{HCH}_{3}$ & $9 / 7$ & $4.5 \times 5.7$ \\
\hline$\left(\mathrm{CH}_{3} \mathrm{CH}_{2}\right)_{2} \mathrm{~N}^{+} \mathrm{HCH}_{3}$ & $8 / 3$ & $4.5 \times 5.7$ \\
\hline \multicolumn{3}{|l|}{ Impermeant cations } \\
\hline $\mathrm{HOCH}_{2} \mathrm{CH}_{2} \mathrm{~N}^{+} \mathrm{H}\left(\mathrm{CH}_{2} \mathrm{CH}_{3}\right)_{2}$ & $5 / 1$ & $4.5 \times 7.4$ \\
\hline$\left(\mathrm{HOCH}_{2} \mathrm{CH}_{2}\right)_{3} \mathrm{~N}^{+} \mathrm{H}$ & $11 / 5$ & $4.5 \times 9.0$ \\
\hline$\left(\mathrm{CH}_{3}\right)_{4} \mathrm{~N}^{+}$ & $7 / 3$ & $5.4 \times 5.4$ \\
\hline$\left(\mathrm{CH}_{3} \mathrm{CH}_{2}\right)_{4} \mathrm{~N}^{+}$ & $4 / 1$ & $7.5 \times 7.5$ \\
\hline $\mathrm{HOCH}_{2} \mathrm{CH}_{2} \mathrm{~N}^{+}\left(\mathrm{CH}_{3}\right)_{3}$ & $12 / 8$ & $5.4 \times 5.4$ \\
\hline$\left(\mathrm{HOCH}_{2}\right)_{3} \mathrm{CN}^{+} \mathrm{H}_{3}$ & $4 / 1$ & $5.4 \times 5.4$ \\
\hline
\end{tabular}

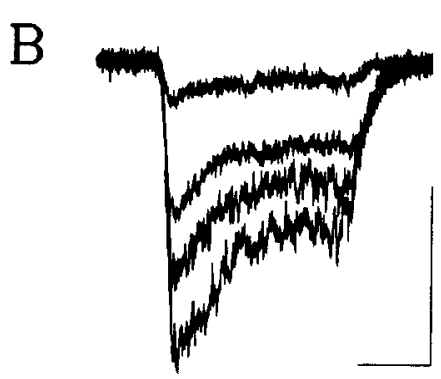

$$
\begin{aligned}
& \left(\mathrm{CH}_{3} \mathrm{CH}_{2}\right)_{2} \mathrm{~N}^{+} \mathrm{HCH}_{3} \\
& \left(\mathrm{HOCH}_{2} \mathrm{CH}_{2}\right)_{2} \mathrm{~N}^{+} \mathrm{HCH}_{3} \\
& \mathrm{CH}_{3} \mathrm{CH}_{2} \mathrm{~N}^{+} \mathrm{H}\left(\mathrm{CH}_{3}\right)_{2} \\
& \mathrm{HOCH}_{2} \mathrm{CH}_{2} \mathrm{~N}^{+} \mathrm{H}\left(\mathrm{CH}_{3}\right)_{2}
\end{aligned}
$$

The minimum cross section of the NMDA receptor pore was estimated by measuring currents carried by organic cations. The minimum two-dimensional size associated with each cation was estimated by constructing CPK spacefilling models of the cations and finding the smallest two-dimensional slot that could accommodate the models. Only the first six organic cations can carry current; the rest are unable to pass through the channel.

ammonium derivative, $\left(\mathrm{CH}_{3}\right)_{4} \mathrm{~N}^{+}$(tetramethylammonium, TMA), is not a permeant cation. Even relatively large, asymmetric cations can pass through if they can present a small dimension, but the pore is impermeable to all tetra- $n$-alkylammonium cations tested. The results indicate that the narrowest cross section of the pore is rectangular, $\approx 0.45 \times 0.57 \mathrm{~nm}$ (Table $1)$.

Tests were conducted to verify that the organic cations properly detected the narrowest cross-sectional area of the pore. Our inability to see inward current carried by the large organic cations could have been the result of allosteric inhibition of the receptor, not an inability to pass through the narrowest region. In one test, 1 or $5 \mathrm{mM} \mathrm{Cs}^{+}$was added to impermeant solutions of $\mathrm{HOCH}_{2} \mathrm{CH}_{2} \mathrm{~N}^{+}\left(\mathrm{CH}_{3}\right)_{3}$ (Fig. $2 A$ ) or $\left(\mathrm{HOCH}_{2} \mathrm{CH}_{2}\right)_{3} \mathrm{~N}^{+} \mathrm{H}$ (Fig. $2 B$ ). The results show that the NMDA receptor channels can open and pass inward $\mathrm{Cs}^{+}$current in the presence of these impermeant organic cations. Another test showed that outward currents carried by internal $\mathrm{Cs}^{+}$through NMDA receptors could he measured in an external impermeant solution of $\mathrm{HOCH}_{2} \mathrm{CH}_{2} \mathrm{~N}^{+}\left(\mathrm{CH}_{3}\right)_{3}$ (Fig. $2 \mathrm{C}$ ). The external cation could not carry inward current, but in the same cell at more positive hold potentials outward $\mathrm{Cs}^{+}$currents were activated by NMDA. These results show that the impermeant cations are not altering the channel in some unexpected way; rather, these organic cations are too large to pass through the pore.

\section{Voltage dependence for open-channel blockade with simple tetra-n-alkylammonium cations}

The next step to understand the voltage dependence for openchannel blockade is to examine the simplest, smallest impermeant cation, which is TMA. Blockade of NMDA receptor currents by external TMA is described by binding at a site that is $61 \% \pm 3(n=6)$ of the way through the membrane potential field (Fig. $3 A$ ). When added from the inside, TMA detects $34 \%$ $\pm 6(n=3)$ of the field (Fig. $3 B)$. These results are straightforward to interpret. TMA can reach the same constriction in ade. A series of different sized ammonium derivatives was studied to determine which ones could pass through the channel and carry current (Fig. 1). Inward-going currents were measured in pure external solutions of the ammonium derivatives. Relatively large nonsymmetric tri-ammonium cations up to the size of $\left(\mathrm{HOCH}_{2} \mathrm{CH}_{2}\right)_{2} \mathrm{~N}^{+} \mathrm{HCH}_{3}$ can permeate by aligning their smallest dimension along the pore (Fig. $1 A, B$ ). Larger tri-ammonium derivatives cannot fit through the pore. The smallest symmetric 


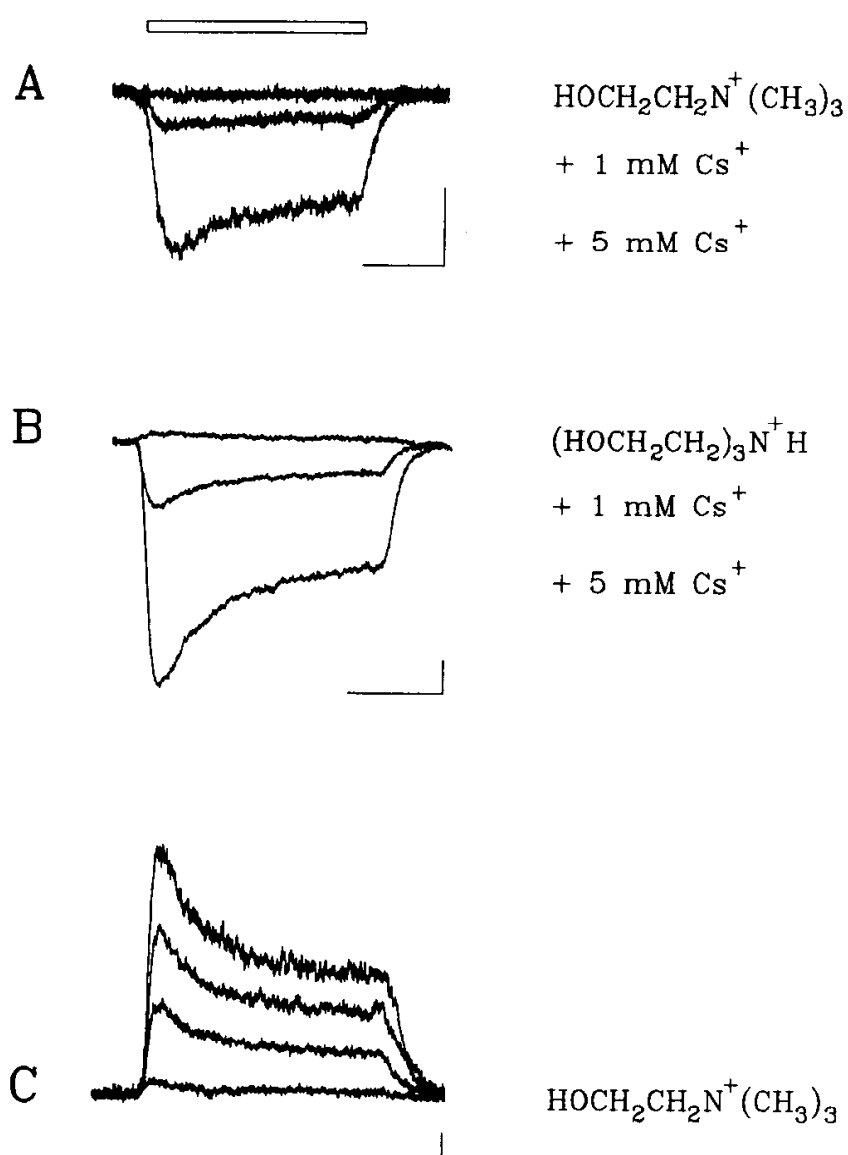

Figure 2. Three tests show that the NMDA receptors function properly in external solutions of impermeant organic cations. These examples of whole-cell currents where induced by application of NMDA $(50 \mu \mathrm{M}, A ; 80 \mu \mathrm{M}, B ; 40 \mu \mathrm{M}, C)$ and glycine $(10 \mu \mathrm{M}, A ; 20 \mu \mathrm{M}, B ; 10$ $\mu \mathrm{M}, C$ ) during the time labeled by the open bar. The ammonium compound listed next to the currents is present at $150 \mathrm{~mm}$ for each cell. Table 1 shows that the external cations, $\mathrm{HOCH}_{2} \mathrm{CH}_{2} \mathrm{~N}^{+}\left(\mathrm{CH}_{3}\right)_{3}$ and $\left(\mathrm{HOCH}_{2} \mathrm{CH}_{2}\right)_{3} \mathrm{~N}^{+} \mathrm{H}$, are impermeant cations. $A$, In a pure solution of the impermeant ammonium compound, no currents are induced by agonist. When 1 or $5 \mathrm{mM} \mathrm{Cs}^{+}$is added to the external solution, the same protocol with the same cell induces current. The result indicates that the NMDA receptors can open and pass current, but the ammonium compound is too large to pass through. The impermeant internal solution contained $145 \mathrm{mM} \mathrm{NMDG}{ }^{+}$, and the holding potential was -50 $\mathrm{mV} . B$, In a different cell using a different impermeant ammonium compound, again current is seen only after 1 or $5 \mathrm{mM} \mathrm{Cs}^{+}$is added to the external solution. The impermeant internal solution contained $145 \mathrm{~mm}$ $\mathrm{NMDG}^{+}$, and the holding potential was $-50 \mathrm{mV}$. The small outward current seen in pure external impermeant cation arises because the internal exchange had not completely removed all endogenous internal cations. $C$, In a third cell, there are no inward currents in a pure external solution of the impermeant ammonium cation. At each holding potential $(-60,0,20,40 \mathrm{mV})$, however, there are outward currents carried by the $10 \mathrm{mM} \mathrm{Cs}^{+}$added to the internal solution of $145 \mathrm{mM} \mathrm{NMDG}^{+}$. Calibration: $10 \mathrm{pA}, 1 \mathrm{sec}$.

the pore from both sides of the membrane. That constriction is likely to be the position of the single-occupancy binding site for all permeant cations (described previously by Zarei and Dani, 1994). The match of the inside and outside voltage dependencies (adding up to a total of nearly 100\%) indicates that the narrowest region is short.

After obtaining the straightforward results with TMA, the voltage-dependent blockade by progressively larger tetra- $n$-alkylammonium cations was studied. The results are summarized
A

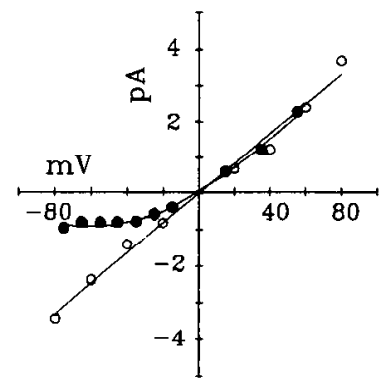

B

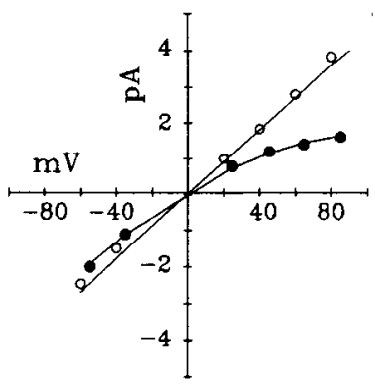

Figure 3. Voltage-dependent blockade by TMA determined from individual current-voltage relations constructed from single-channel currents. In both cases, the linear control current-voltage relation $(O)$ was obtained with pure symmetrical $50 \mathrm{mM} \mathrm{Cs}^{+}$as the permeant cation bathing both sides of the membrane. The control was obtained in the same membrane patch with the test current-voltage relation (O). Osmolalities were balanced with sucrose. All of the theoretical curves are based on Equation 1. A, When $150 \mathrm{~mm}$ TMA was added to the external $50 \mathrm{mM} \mathrm{Cs}{ }^{+}$, the inward currents were blocked as though TMA scnsed $64 \%$ of the potential field from the outside with a $K_{d}$ of $370 \mathrm{~mm}$ for this trial. $B$, When $150 \mathrm{~mm}$ TMA was added to the internal $50 \mathrm{~mm} \mathrm{Cs}^{+}$, the outward currents were blocked as though TMA sensed $34 \%$ of the potential field from the inside with a $K_{d}$ of $330 \mathrm{~mm}$ for this trial.

for blockade from the inside in Figure 4 and from the outside in Figure 5. The intercsting surprise was provided by the impermeant cation, tetraethylammonium (TEA), which is the next larger cation after TMA in the tetra- $n$-alkylammonium series. When applied from the inside, TEA penetrates through nearly the same proportion of the membrane field as does TMA (Fig. 4). TEA detects $32 \% \pm 3(n=3)$ of the field, and TMA detects $34 \%$. TEA is larger than TMA, so the narrowing of the channel Inight prevent the center of TEA from passing all the way to the constriction reached by TMA. We expected a similar result when TEA was applied from the outside. To our surprise, however, TEA detected $90 \% \pm 3(n=7)$ of the field from the outside (Fig. 5). That amount is greater than is detected by TMA, and in total, TEA detects $90 \%+32 \%$ or $122 \%$ of the field. To be certain that this result is correct, the voltage dependence of blockade was tested with different concentrations of TEA. As shown in Figure 6 for TEA, neither the voltage dependence nor the $K_{d}$ of blockade is affected by the concentration of the block$\mathrm{er}$, as was the case for all the tetra- $n$-alkylammonium cations tested.

The same experiments with the next two larger tetra- $n$-alkylammonium cations filled in the information needed to devise a hypothesis. Tetra- $n$-propylammonium (TPA) does not block from the inside at $150 \mathrm{mM}$ either because it is too large or has a very low affinity for binding (Fig. 4). That result is consistent with the pattern of lower affinity and voltage dependence seen with TEA relative to TMA from the inside. From the outside, TPA and tetra- $n$-butylammonium (TBA) sense nearly the same proportion of the field as TMA (Fig. 5). TPA senses $57 \% \pm 5$ $(n=6)$ of the field, and TBA senses $50 \% \pm 5(n=4)$.

\section{Discussion}

Structural considerations for the NMDA receptor pore

Because the NMDA receptor channel is impermeable to the symmetrical cation TMA, but is permeable to larger asymmetrical cations, we conclude that the narrowest cross section of the pore is a rectangular with dimensions of at least $0.45 \times 0.57$ 


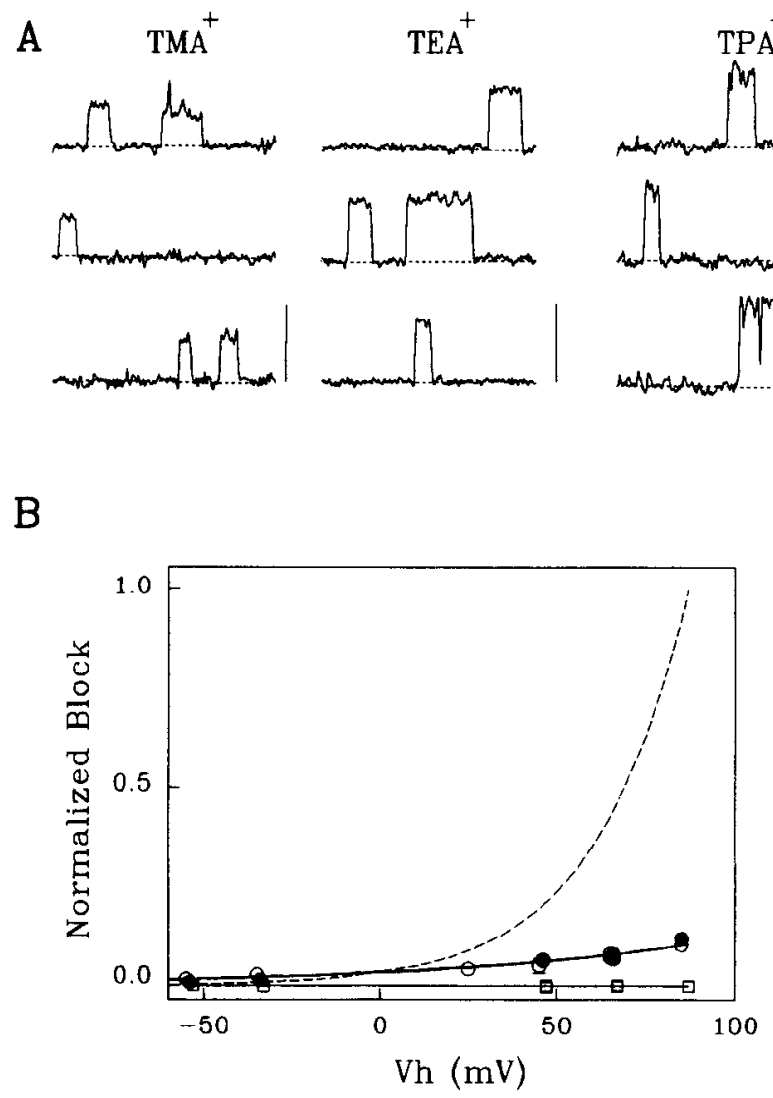

Figure 4. A summary of open-channel blockade by internal tetra- $n$ alkylammonium cations. $A$, NMDA-activated inside-out single-channel currents are shown in internal solutions that contain $50 \mathrm{~mm} \mathrm{Cs}$ ' with TMA (left), TEA (middle), or TPA (right), each at $150 \mathrm{mM}$. The solution bathing the external surface of the membrane contains pure $50 \mathrm{~mm}$ $\mathrm{Cs}^{+}$as the permeant cation, and the osmolalities were adjusted with sucrose. After correcting for junction potentials, the holding potentials are $65 \mathrm{mV}, 66 \mathrm{mV}$, and $67 \mathrm{mV}$ (from left to right). The vertical bar next to each set of traces represents the single-channel amplitude seen when no blocker is present. Calibration: $2 \mathrm{pA}, 10 \mathrm{msec} . B$, Normalized block is plotted versus the holding potential for the single-channel currents. The data are fitted using Equation 2 after normalizing to the block at the largest potential studied, $85 \mathrm{mV}$. By using Equation 2 to normalize the blockade, data obtained at different blocker concentrations can be compared. The dashed line is a theoretical curve that indicates the block that would be seen if $100 \%$ of the membrane field were detected by a blocking cation. The theoretical curves (solid lines) indicate that the fractions of the membrane field sensed by TMA and TEA are $34 \%$ and $32 \%$ with $K_{d}$ equal to $330 \mathrm{~mm}$ and $1200 \mathrm{~mm}$, respectively. No block was seen with $150 \mathrm{~mm}$ TPA applied from the inside. TMA, O; TEA, O; TPA, $\square$.

$\mathrm{nm}$ or $0.26 \mathrm{~nm}^{2}$ (Fig. $7 A$; see Vyklicky et al., 1988). It is interesting to compare this size with the voltage-dependent $\mathrm{Ca}^{2+}$ channel that was estimated to be about $0.28 \mathrm{~nm}^{2}$ (McCleskey and Almers, 1985). The similarity in size of the narrowest cross sections may reflect that both of these channels must provide ligands for the appropriate coordination of $\mathrm{Ca}^{2+}$ during permeation. The actual molecular mechanism of $\mathrm{Ca}^{2+}$ permeation, however, is different in the two channel types (see Almers and McCleskey, 1984; Hess and Tsien, 1984; Yang et al., 1993; Zarei and Dani, 1994).

Another interesting comparison is with the muscle nicotinic acetylcholine receptor (nAChR). This channel has a wider minimum cross section $\left(0.65 \times 0.65 \mathrm{~nm}\right.$ or $0.42 \mathrm{~nm}^{2}$; Dwyer et al., 1980; Dani, 1989). Hydrated $\mathrm{Mg}^{2+}$ has dimensions of about 0.64

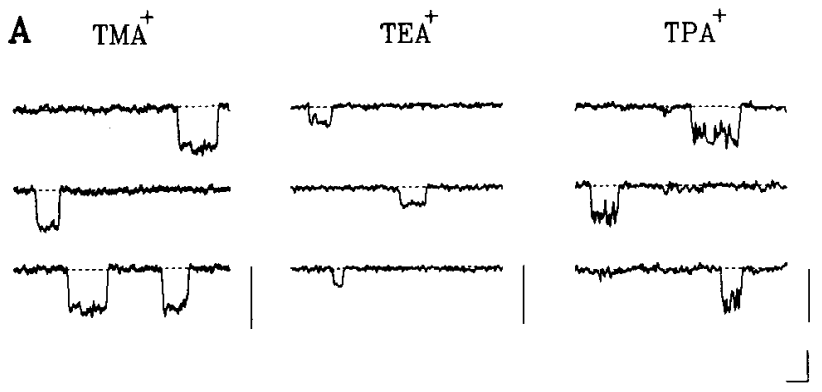

B
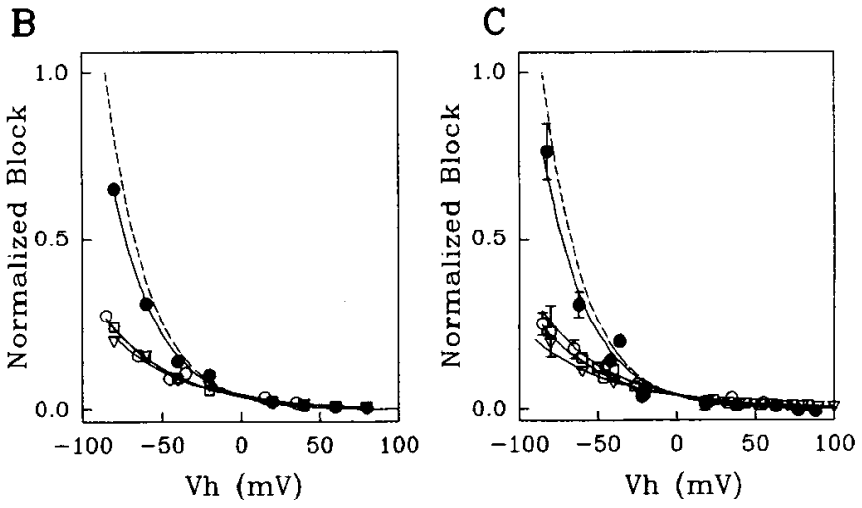

Figure 5. A summary of open-channel blockade by external tetra- $n$ alkylammonium cations. $A$, NMDA-activated outside-out single-channel currents are shown at $-45 \mathrm{mV}$ (TMA, left), $-42 \mathrm{mV}$ (TEA, middle), and $-40 \mathrm{mV}$ (TPA, right) after correcting for junction potentials. The external solution contains $50 \mathrm{mM} \mathrm{Cs}^{+}$and $150 \mathrm{~mm}$ TMA or $25 \mathrm{~mm}$ TEA or $0.5 \mathrm{~mm}$ TPA. The internal solution contained pure $50 \mathrm{~mm} \mathrm{Cs}^{+}$ but no tetra-n-alkylammonium compounds. The osmolalities were balanced by sucrose. The vertical bars next to each set of traces represent the single-channel amplitudes seen when no blocker is present at that holding potential. Calibration: $1 \mathrm{pA}, 10 \mathrm{msec}$. Normalized block is plotted versus holding potential for outside-out single-channel currents $(B)$ and whole-cell currents $(C)$. The data are fitted using Equation 2 after normalizing to the block at the most negative potential studied, -85 $\mathrm{mV}$. The theoretical dashed curves indicate the block that would be seen if $100 \%$ of the membrane field were detected by a blocking cation. A summary of the data is as follows. For single-channel measurements with multiple trials per patch, the percentage of the membrane field sensed is $60 \%, 64 \%$ ( $n=2$ patches) with $K_{d}$ of 470 and $370 \mathrm{mM}$ for TMA (O); $85 \%, 90 \%(n=2), K_{d}$ of 50 and $57 \mathrm{mM}$ for TEA $(\bigcirc) ; 55 \%$, $59 \%(n=2), K_{d}$ of 3.4 and 1.3 for TPA $(\square) ; 55 \%, K_{d}$ of 0.3 for TBA $(\nabla)$. For whole-cell measurements $(C)$, the percentage of the membrane field sensed is $61 \% \pm 4, K_{d}=540 \pm 51(n=4)$ for TMA $(O) ; 91 \%$ $\pm 3, K_{d}=53 \pm 7(n=5)$ for TEA $(0) ; 57 \% \pm 8, K_{d}=7 \pm 0.4(n$ $=4)$ for TPA $(\square)$; $49 \% \pm 5, K_{d}=3 \pm 0.8(n=3)$ for TBA $(\nabla)$. Note that only TEA senses a significantly greater proportion of the membrane field than the other blocking cations.

$\times 0.64 \mathrm{~nm}$, allowing it to permeate the nAChR (Adams et al., 1980; Dani and Eisenman, 1987; Decker and Dani, 1990), but that size is too large for the NMDA receptor. It is probably the hydrated form of $\mathrm{Mg}^{2+}$ that blocks the NMDA receptor because dehydration is slow (see Lansman et al., 1986; Mayer and Westbrook, 1987). At very negative holding potentials, the high driving force provides energy to help strip the water molecules off more rapidly and the block is partially relieved as $\mathrm{Mg}^{2+}$ is driven through the pore (Mayer and Westbrook, 1987).

The general shape of the $\mathrm{nAChR}$ with a wide external vestibule and a smaller internal entrance (Unwin, 1993) may also apply for the NMDA receptor pore based on the sidedness of blockade by the tetra- $n$-alkylammonium compounds. All of the compounds block from the outside, and the affinity increases as 
A
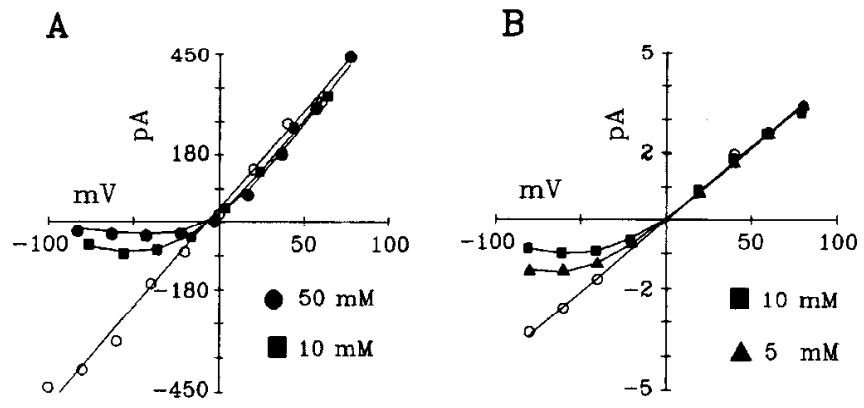

Figure 6. These current-voltage relations show that open-channel blockade quantitatively does not depend on the concentration of TEA. The current-voltage relations were constructed from whole-cell currents $(A)$ or single-channel currents $(B)$ and were normalized so that the control currents $(O)$ from each trial matched. This normalization accounted for a different number of channels in each cell or patch. The linear control current-voltage relations were obtained with pure symmetrical $50 \mathrm{mM} \mathrm{Cs}^{+}$as the permeant cation bathing both sides of the membrane. Osmolalities were balanced with sucrose. All of the theoretical curves are based on Equation 1. For the whole-cell currents in $A$, the data are described best for the two labeled concentrations of TEA by the following: at $10 \mathrm{~mm}$ TEA $(\square), 90 \%$ of the potential field is sensed with a $K_{d}$ of $35 \mathrm{~mm}$; at $50 \mathrm{~mm}$ TEA $(-9), 95 \%$ with a $K_{d}$ of $55 \mathrm{~mm}$. For the singlechannel currents in $B$, the data are described best for the two concentration of TEA by the following: at $10 \mathrm{mM}$ TEA ( $\mathbf{D}), 85 \%$ of the potential field is sensed with a $K_{d}$ of $50 \mathrm{~mm}$; at $5 \mathrm{~mm}$ TEA, $90 \%$ with a $K_{d}$ of $57 \mathrm{~mm}$. These examples of individual determinations of the voltage-dependent blockade show the same amount of variability between different concentrations of TEA as is seen between separate determinations at a single concentration of TEA

methyl groups are added: TMA $\left(K_{d} \approx 500 \mathrm{mM}\right)$, TEA $\left(K_{d} \approx 53\right.$ $\mathrm{mM})$, TPA $\left(K_{d} \approx 5 \mathrm{mM}\right)$, TBA $\left(K_{d} \approx 2 \mathrm{mM}\right)$. The increased affinity with size and hydrophobicity is also seen for the nAChR (Adams et al., 1981) and other channels (Armstrong, 1969; French and Shoukimas, 1985). As described and reviewed by Sanchez et al. (1986), this increased affinity could be largely entropy driven with the organic cation preferring surfaces of the channel protein over bulk water. The external blockade suggests a large external entrance that we have schematically represented in Figure $7 B$. From the inside, only the smaller tetra- $n$-alkylammonium compounds block the NMDA receptor, and the affinity falls dramatically as methyl groups are added: TMA $\left(K_{d} \approx 330\right.$ $\mathrm{mM})$, TEA $\left(K_{d} \approx 1200 \mathrm{~mm}\right)$. The larger compounds may havc too low of an affinity to block, but it is possible that they are too large to enter the smaller internal entrance. The second alternative is appealing in its similarity to the nAChR, where the small internal entrance to the $\mathrm{nAChR}$ prevents blockade by large organic cations from the inside (see Sanchez et al., 1986). Therefore, the internal entrance is represented as narrower in Figure $7 B$.

The final similarity to the $\mathrm{nAChR}$ is that the narrowest region is short. The nAChR has a narrowest cross section that is short in length (0.3-0.6 nm; Dani, 1989), and voltage-dependent block by TMA suggests that the same is true for the NMDA receptor. Because all of the compounds have a large voltage dependence from the outside and TMA seems to reach nearly the same position in the membrane field from both sides of the membrane, that implies that the narrow region is short. Figure $7 B$ represents the minimum cross section at one position (labeled by an arrow). The narrow region extends out from that position for only a short distance to account for the interaction between the blocking site and the permeant-ion site as described below.
Hypothesis that explains the differences in voltage-dependent blockade

A series of independent experiments has shown that the NMDA receptor channel behaves as a single-occupancy channel for small monovalent and divalent permeant cations (Zarei and Dani, 1994). Stated more precisely, one small permeant cation at a time occupies a binding site or sites that are located directly in the permeation pathway in the narrowest portion of the pore. For ease of discussion, we will refer to the single-occupancy binding site(s) in the narrowest region as the "permeant-ion site" (located at the arrow in Fig. $7 B-H$ ).

A reasonable interpretation for the difference in the voltage dependence seen with open-channel blockers is the following. The smallest open-channel blocker, TMA, passes all the way to the narrowest constriction in the pore. TMA senses $61 \%$ of the membrane field from the outside and $34 \%$ from the inside. Because TMA senses a total of $95 \%(61 \%+34 \%)$ of the field, TMA seems to reach nearly the same position from both sides of the membrane, indicating that the narrowest cross section is short. That conclusion is schematically represented for TMA blockade from the outside (Fig. 7C) and the inside (Fig. 7D). From both sides of the membrane, the binding site for TMA overlaps with the permeant-ion site. Therefore, TMA and a permeant cation cannot both occupy that position at the same time.

TEA is a larger cation that reaches nearly the same position as TMA from the inside. As shown in Figure $7 F$. TEA from the inside overlaps with the permeant-ion site. Therefore, there cannot be interacting sites because only one of them can be occupied at a time. We hypothesize that from the outside the center of TEA does not penetrate quite as deeply into the pore as TMA. Unlike the situation from the inside, TEA reaches a position (binding site) that is separate but electrostatically coupled to the permeant-ion site (Fig. $7 E$ ). It is this coupling between the sites that produces the high voltage dependence for blockade from the outside $(90 \%)$. TEA not only senses the voltage up to its blocking site ( $\approx 60 \%$ ); it also is coupled electrostatically to part of the remaining field through the movement of the permeant cation off its site. This conclusion would suggest that much of the voltage drop occurs in a length of about $1.0 \mathrm{~nm}$ adjacent to the narrowest cross section. This hypothesis is consistent with that of Park and Miller (1992), who estimated significant electrostatic interaction over a comparable distance in the $\mathrm{Ca}^{2+}$-activated $\mathrm{K}^{+}$channel.

The next larger cation in the series, TPA either is too large to enter the pore from the inside or its affinity is too low to detect blockade. From the outside, however, TPA and TBA sense nearly the same proportion of the field as does TMA. Thus, we hypothesize that TEA, TPA, and TBA are all reaching a similar position just slightly external to the narrowest constriction, which is the position reached by permeant cations and TMA. The three-carbon and four-carbon arms of TPA and TBA can reach from the blocking site to the permeant-ion site. Therefore, there cannot be multiple-occupancy effects in this case because TPA or TBA occupy the permeant-ion site while they are at the blocking site (Fig. 7G,H). Given the length of the side arms of TPA and TBA, this argument indicates that the narrow region extends outward about $0.6 \mathrm{~nm}$ from the minimum cross section, consistent with the distance suggested by the electrostatic interactions between TEA and the permeant-ion site (Park and Miller, 1992). The exact position of the center of a blocking cation will depend on its size and shape as well as chemical 


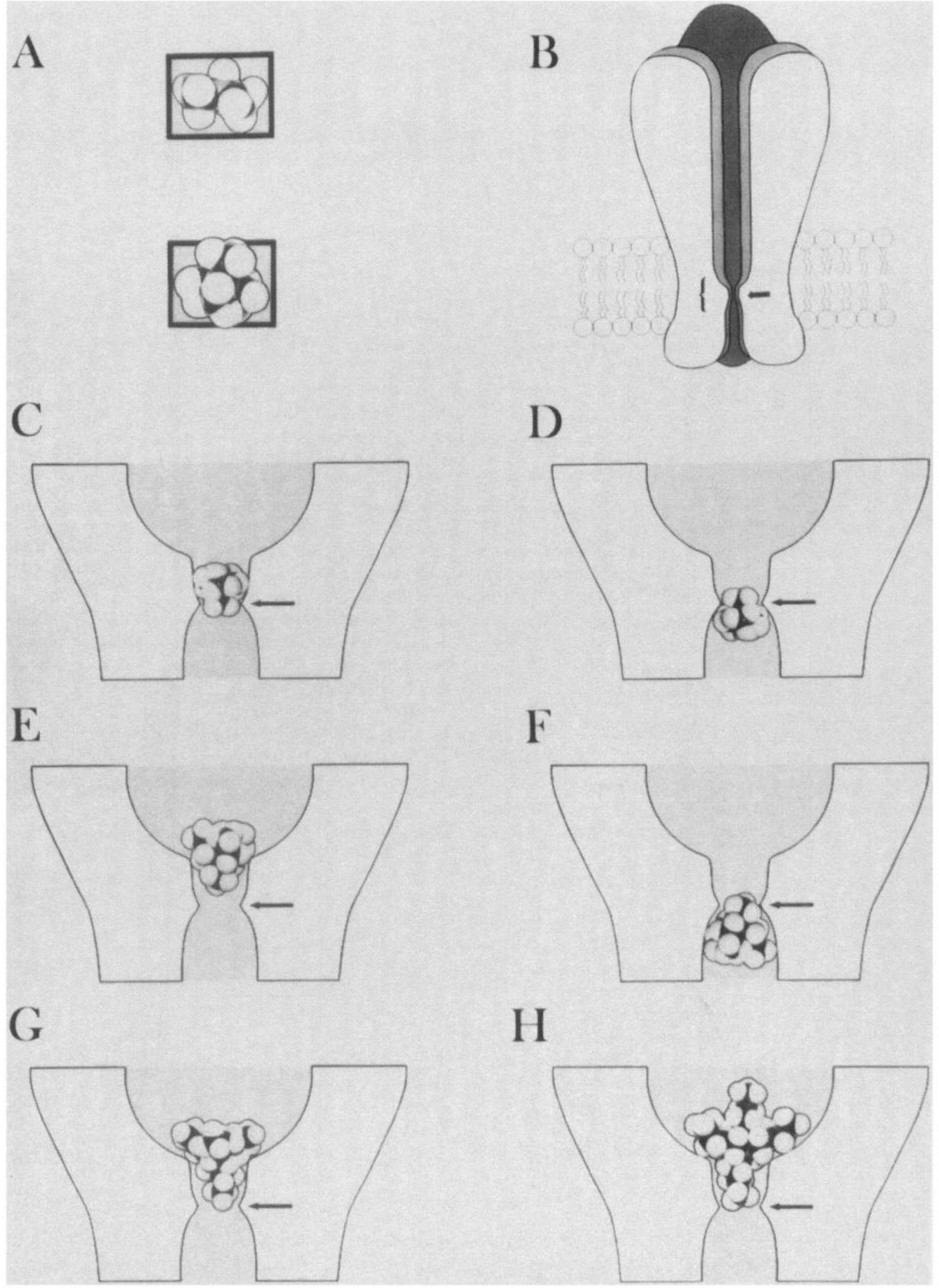

Figure 7. Hypothetical schematic representations of the NMDA receptor pore used to illustrate open-channel blockade. A, A representation of a straight-on view of the $0.45 \times 0.57 \mathrm{~nm}$ minimum cross section of the NMDA receptor pore showing that $\mathrm{TMA}^{\mathrm{N}}$ does not fit through but $\left(\mathrm{CH}_{3}\right)_{3} \mathrm{~N}^{+}$ (trimethylammonium) can pass through the opening by properly aligning along the axis of the pore. $B$, A cut-away representation of the full length of the open NMDA receptor pore. The horizontal arrow indicates the minimum cross section shown in $A$. The bracket $(\{)$ indicates the length of the pore adjacent to the narrowest cross section that is represented in $\mathrm{C}-\mathrm{H}$. The remaining schematic drawings are expanded views of the narrow region depicting block by external TMA $(C)$, internal TMA $(D)$, external TEA $(E)$, internal TEA $(F)$, external TPA $(G)$, and external TBA $(H)$, Note that TEA can reach the narrowest cross section from the intracellular part of the channel $(F)$, but cannot reach the narrowest cross section from the extracellular part of the channel $(E)$. 
A

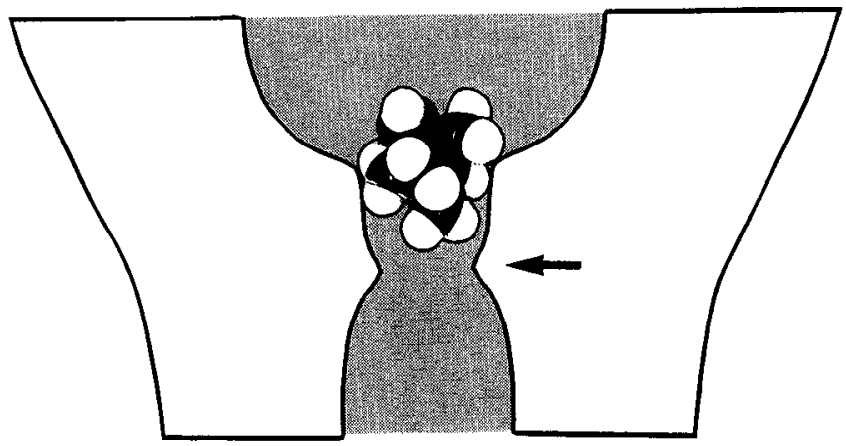

B

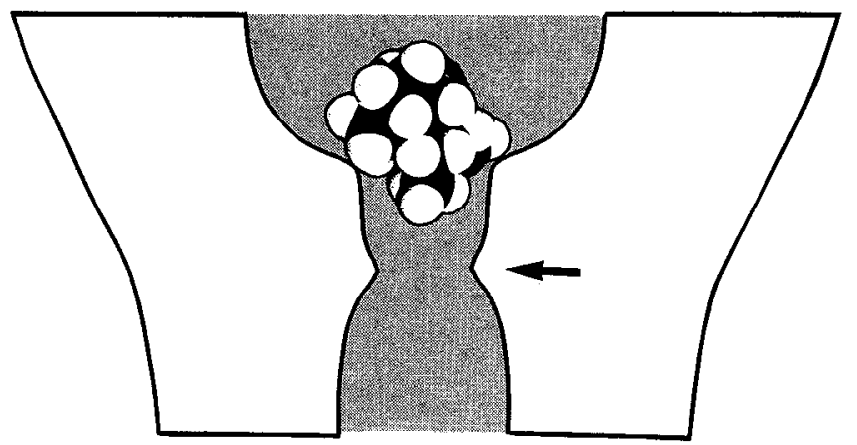

Figure 8. Schematic cut-away representation of the narrow region of the NMDA receptor pore blocked by hydrated $\mathrm{Mg}^{2+}(A)$ or ketamine $(B)$. Note that both hydrated $\mathrm{Mg}^{2+}$ and ketamine block at the position reached by TEA, and that the permeant-ion site (arrow) can be simultaneously occupied by a cation.

interactions. Although there are likely to be exceptions, this structural perspective accounts for single occupancy by small permeant ions while still allowing ionic interaction leading to high voltage dependencies for blockade by some, but not all, impermeant cations.

Other cations that have high voltage dependencies for blockade have sizes (areas) that enable them to occupy the blocking site and electrostatically interact with the permeant-ion site, as does TEA (Fig. $7 E$ ). Figure 8 shows that a cation can occupy the permeant-ion site while hydrated $\mathrm{Mg}^{2+}$ or ketamine are bound to the blocking site, thus allowing electrostatic interaction. Therefore, the structural basis proposed here is consistent with ketamine and MK-801 achieving their high voltage dependence for blockade from the outside (Mayer et al., 1988) by a mechanism like that proposed here for TEA. The most well studied and most important blocking ion is $\mathrm{Mg}^{2+}$. Although different values have been reported for the voltage dependence of blockade from the outside, the reported percentage of the field that is detected has always been greater than $70 \%$ (Ascher and Nowak, 1988; Jahr and Stevens, 1990; Chen and Huang, 1992). In addition, $\mathrm{Mg}^{2+}$ is reported to detect $35 \%$ of the field from the inside (Johnson and Ascher, 1990), indicating it reaches the same position reached by TMA and TEA. Therefore, there is agrecment in the literature over the issue that is most important for devising an explanation: the total proportion of the field detected by $\mathrm{Mg}^{2+}$ from the inside and outside is greater than $100 \%$. Hydrated $\mathrm{Mg}^{2+}$ occupies the blocking site and has a large volt- age dependence for block from the outside because of coupling to the movement of the permeant cation off of its binding site. Although the agreement in the literature is very good, some of the reported differences in the voltage dependence for block from the outside may arise from different subtypes of NMDA receptors. In addition, a different voltage dependence could arise from $\mathrm{Mg}^{2+}$ at the blocking site coupling to a monovalent cation or $\mathrm{Ca}^{2+}$ at the permeant-ion site, which would depend on the composition of the experimental solutions. $\mathrm{Mg}^{2+}$ would have an apparently higher voltage dependence for block if it were coupled to the movement of $\mathrm{Ca}^{2}$. While moving through the same proportion of the membrane field, $\mathrm{Ca}^{2+}$ would appear to have twice the voltage dependence of a monovalent cation. Therefore, coupling to the movement of $\mathrm{Ca}^{2+}$ would give $\mathrm{Mg}^{2+}$ a greater voltage dependence for blockade.

The hypothesis for the voltage dependence of NMDA receptor blockade also is consistent with the finding that $\mathrm{Mg}^{2+}$ block is diminished as the permeant ion concentration is increased (Zarei and Dani, 1994). Increasing the permeant ion concentration would increase the occupancy of the permeant-ion sitc and that would electrostatically repel $\mathrm{Mg}^{2+}$ from the blocking site. The overall effect would have the appearance of decreasing the affinity of $\mathrm{Mg}^{2+}$ for the blocking site. Those competition experiments also showed that there are no (single-file) binding sites for small permeant cations external to the blocking site for $\mathrm{Mg}^{2+}$ (Zarei and Dani, 1994). The schematic representations of blockade in Figures 7 and 8 are consistent with those results.

\section{References}

Adams DJ, Dwyer TM, Hille B (1980) The permeability of endplate channels to monovalent and divalent metal cations. J Gen Physiol 75:493-510.

Adams DJ, Nonner W, Dwyer TM, Hille B (1981) Block of endplate channels by permeant cations in frog skeletal muscle. J Gen Physiol $78: 593-615$

Almers W, McCleskey EW (1984) Non-selective conductance in calcium channels of frog muscle: calcium selectivity in a single-file pore. J Physiol (Lond) 353:585-608.

Amador M, Dani JA (1991a) Protein kinase inhibitor, H-7, directly affects $N$-methyl-D-aspartate receptor channels. Neurosci Lett 124 : 251-255.

Amador M, Dani JA (1991b) MK-801 inhibition of nicotinic acetylcholine receptor channels. Synapse 7:207-215.

Armstrong CM (1969) Inactivation of the potassium conductance and related phenomena caused by quaternary ammonium ion injection in squid axons. J Gen Physiol 54:553-575.

Ascher P, Nowak L (1988) The role of divalent cations in the $N$-methyl-D-aspartate responses of mouse central neurones in culture. J Physiol (Lond) 399:247-266.

Bliss TVP, Collingridge GL (1993) A synaptic model of memory: longterm potentiation in the hippocampus. Nature 361:31-39.

Burnashev N, Schoepfer R, Monyer H, Ruppersberg JP, Gunther W, Seeburg PH, Sakmann B (1992) Control by asparagine residues of calcium permeability and magnesium blockade in the NMD $\Lambda$ receptor. Science 257:1415-1419.

Chen Li, Huang LM (1992) Protein kinase C reduces $\mathrm{Mg}^{2+}$ block of NMDA receptor channels as a mechanism of modulation. Nature 356 : $521-523$.

Dani JA (1989) Open channel structure and ion binding sites of the nicotinic acetylcholine receptor channel. J Neurosci 9:884-892.

Dani JA, Eisenman G (1987) Monovalent and divalent cation permeation in acetylcholine receptor channels: ion transport related to structure. J Gen Physiol 89:959-983.

Decker ER, Dani JA (1990) Calcium permeability of the nicotinic acetylcholine receptor: the single-channel calcium influx is significant. J Neurosci 10:3413-3420.

Dwyer TM, Adams DJ, Hille B (1980) The permeability of the endplate channel to organic cations in frog muscle. J Gen Physiol 75: $469-492$. 
French RJ, Shoukimas JJ (1985) An ion's view of the potassium channel. The structure of the permeation pathway as sensed by a variety of blocking ions. J Gen Physiol 85:669-698.

Hamill OP, Marty A, Neher E, Sakmann B, Sigworth FJ (1981) Improved patch-clamp techniques for high-resolution current recording from cells and cell-free membrane patches. Pfluegers Arch 391:85100.

Hess P, Tsien RW (1984) Mechanism of ion permeation through calcium channels. Nature 309:453-456.

Ionore T, Davies SN, Drejer J, Fletcher EJ, Jacobsen P, Lodge D, Nielsen FE (1988) Quinoxalinediones: potent competitive non-NMDA glutamate receptor antagonists. Science 241:701-703.

Huettner JE, Baughman RW (1986) Primary culture of identified neurons from the visual cortex of postnatal rats. J Neurosci 6:3044-3060.

Jahr CE, Stevens CF (1990) A quantitative description of NMDA receptor-channel kinetic behavior. J Neurosci 10:1830-1837.

Johnson JW, Ascher P (1990) Voltage-dependent block by intracellular $\mathrm{Mg}^{2+}$ on NMDA-activated channels. Biophys J 57:1085-1090.

Lansman JB, Hess P, Tsien RW (1986) Blockade of current through single calcium channels by $\mathrm{Cd}^{2+}, \mathrm{Mg}^{2+}$, and $\mathrm{Ca}^{2+}$. Voltage and concentration dependence of calcium entry into the pore. J Gen Physiol $88: 321-347$.

MacDermott AB, Mayer ML, Westbrook GL, Smith SJ, Barker JL (1986) NMDA-receptor activation increases cytoplasmic calcium concentration in cultured spinal cord neurones. Nature 321:519-522.

Madison DV, Malenka RC, Nicoll RA (1991) Mechanisms underlying long-term potentiation of synaptic transmission. Annu Rev Neurosci 14:379-397.

Mayer ML, Westbrook GL (1987) Permeation and block of $N$-methylD-aspartic acid receptor channels by divalent cations in mouse cultured central neurones. J Physiol (Lond) 394:501-527.

Mayer ML, Westbrook GL, Guthrie PB (1984) Voltage-dependent block by $\mathrm{Mg}^{2+}$ of NMDA responses in spinal cord neurones. Nature 309:261-263.

Mayer ML, Westbrook GL, Vyklicky L Jr (1988) Sites of antagonist action on $N$-methyl-D-aspartic acid receptors studied using fluctuation analysis and a rapid perfusion technique. J Neurophysiol 60:645-663.

McCleskey EW, Almers W (1985) The $\mathrm{Ca}^{2+}$ channel in skeletal muscle is a large pore. Proc Natl Acad Sci USA 82:7149-7153.

Mori H, Masaki H, Yamakura T, Mishina M (1992) Identification by mutagenesis of a $\mathrm{Mg}^{2+}$-block site of the NMDA receptor channel. Nature 358:673-675.

Nowak L, Bregestovski P, Ascher P, Herbet A, Prochiantz A (1984) Magnesium gates glutamate-activate channels in mouse central neurones. Nature 307:462-465.

Park C-S, Miller C (1992) Interaction of charybdotoxin with permeant ions inside the pore of the $\mathrm{K}^{+}$channel. Neuron 9:307-313.

Reynolds IJ, Miller RJ (1988) ['II]MK801 binding to the $N$-methyl-Daspartate receptor reveals drug interactions with the zinc and magnesium binding sites. J Pharmacol Exp Ther 247:1025-1031.

Sanchez JA, Dani JA, Siemen D, Hille B (1986) Slow permeation of organic cations in acetylcholine receptor channels. J Gen Physiol 87: 985-1001.

Sernagor E, Kuhn D, Vyklicky L Jr, Mayer ML (1989) Open channel block of NMDA receptor responses evoked by tricyclic antidepressants. Neuron 2:1221-1227.

Unwin N (1993) Neurotransmitter action: opening of ligand-gated ion channels. Neuron Rev [Suppl] 10:31-41.

Vyklicky L Jr, Krusek I, Edwards C (1988) Differences in the pore sizes of the NMDA and kainate cation channels. Neurosci Lett 89: 313-318.

Wong EHF, Kemp JA, Priestley T, Knight AR, Woodruff GN, Iversen LL (1986) The anticonvulsant MK-801 is a potent NMDA antagonist. Proc Natl Acad Sci USA 83:7104-7108.

Woodhull AM (1973) Ionic blockage of sodium channels in nerve. J Gen Physiol 61:687-708.

Yang J, Ellinor PT, Sather WA, Zhang JF, Tsien RW (1993) Molecular determinants of $\mathrm{Ca}^{21}$ selectivity and ion permeation in L-type $\mathrm{Ca}^{2+}$ channels. Nature 366:158-161.

Zarei MM, Dani JA (1994) Ionic permeability characteristics of the $N$-methyl-D-aspartate receptor. J Gen Physiol 103:231-248. 